\title{
Insights into Refractive Surgery and Corneal Light Scatter
}

\author{
An Expert Interview with Leopoldo Spadea \\ Department of Medico-Surgical Sciences and Biotechnologies, Sapienza University of Rome, Italy
}

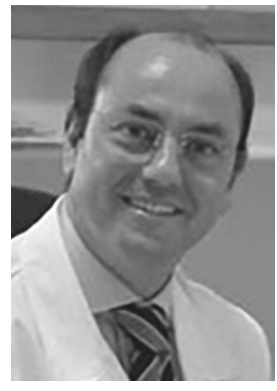

\section{Leopoldo Spadea}

Leopoldo Spadea is an associate clinical professor in ophthalmology, school of medicine, Sapienza University of Rome, Italy. He has previously worked at the University of L'Aquila. He has presented papers at national and international congresses and symposia and has published over 300 scientific publications. In particular, having become an expert in refractive surgery, he has been called upon to present official papers at many international courses and symposia. His interests includes corneal topography, excimer laser refractive procedures (photo refractive keratectomy [PRK] and laser-assisted in situ keratomileusis [LASIK]), cataract surgery and keratoplasty.

\section{Keywords}

AS-optical coherence tomography (OCT), canaloplasty, corneal light scattering, excimer lasers, irregular corneas

Disclosure: Leopoldo Spadea has nothing to declare in relation to this article. No funding was received in the publication of this article. This is an expert interview and as such has not undergone the journal's standard peer review process.

Acknowledgements: Medical writing assistance was provided by Katrina Mountfort, Freelance Medical Writer, supported by Touch Medical Media.

Authorship: All named authors meet the International Committee of Medical Journal Editors (ICMJE) criteria for authorship of this manuscript, take responsibility for the integrity of the work as a whole, and have given final approval to the version to be published. open Access: This article is published under the Creative Commons Attribution Noncommercial License which permits any non-commercial use, distribution, adaptation and reproduction provided the original author(s) and source are given appropriate credit.

Received: 17 June 2017

Published Online: 21 July 2017

Citation: European Ophthalmic Review, 2017;11(1):17-8

Corresponding Author: Leopoldo Spadea, Via Benozzo Gozzoli 34, 00142 Rome, Italy.

E: leopoldo.spadea@uniroma1.it
G ood vision requires maintenance of the transparency and proper refractive shape of the cornea. Any surface structure irregularities can lead to wavefront aberrations and scattering errors. Light scattering in the human cornea causes a reduction of visual quality. In this interview, Leopoldo Spadea of Sapienza University of Rome, Italy, discusses recent advances in refractive surgery, corneal light scatter, the benefits of canaloplasty in cataract surgery in patients with glaucoma and the upcoming European Society of Cataract Surgeons (ESCRS) congress.

\section{Q: What are the advantages and limitations of the use of excimer lasers for irregular corneas?}

Treatment of the irregular astigmatism has been posing a challenge for refractive surgeons. Historically, the alternatives for correction of irregular astigmatism were few, expectations were limited and the consequences were unpredictable anatomically and functionally. In recent years, however, advancements in laser technology have offered us better tools for facing irregular astigmatism. Ultimately, technological advances have led us to two promising customised approaches: one based on wavefront measurements and, especially, one based on corneal topography. By using these techniques, excimer laser surgery provides an accurate tool to reshape the cornea.

\section{Q: What is the impact of corneal light scattering on vision?}

Retinal image quality is degraded by scatter, diffraction and wavefront aberrations (better known as wavefront errors). Besides higher-order aberrations, changes in the transparency of the cornea could also impact on visual performance. The trasparency of the cornea is related to its highly organised structure, and when this complex configuration becomes altered, light scatter is increased, resulting in a changing luminance superimposed upon the retinal image, leading to a reduction in retinal image contrast and possible disability glare. Changes in the ultrastructure of the cornea induced by inflammation, swelling, postsurgical, wound-healing processes can lead to loss of transparency of the cornea. Haze leads to loss of corneal transparency, which can deteriorate patients' visual function by causing glare, loss of contrast sensitivity and decrease in visual acuity. This induces increased corneal light back-scatter, which is thought to occur in many clinical conditions even with different approaches. 


\section{Q: What are the best methods of measuring corneal light scatter?}

Usually, corneal light scatter is evaluated using a slit lamp biomicroscope. The Scheimpflug camera was developed according to the Scheimpflug principle. This non-invasive analysis of the anterior segment detects backscattered light in the different regions of the cornea, called a corneal densitometry map. The confocal microscope allow clinicians to compare the brightness of the haze with that of normal corneas, to identify sources of the elevated haze within the cornea, and to follow progression or regression of haze in patients. Also, a technique called optical coherence tomography has been designed to detect usually faint back-scattered light from corneal tissue.

\section{Q: What presentations are you most looking forward to at this year's ESCRS congress?}

Every year, the ESCRS congress presents the most important international news for cataract and refractive surgeons. This year I am interested in following the novelties in refractive and corneal surgery, with particular regard to the modern techniques of treatment with excimer lasers. $\square$ 